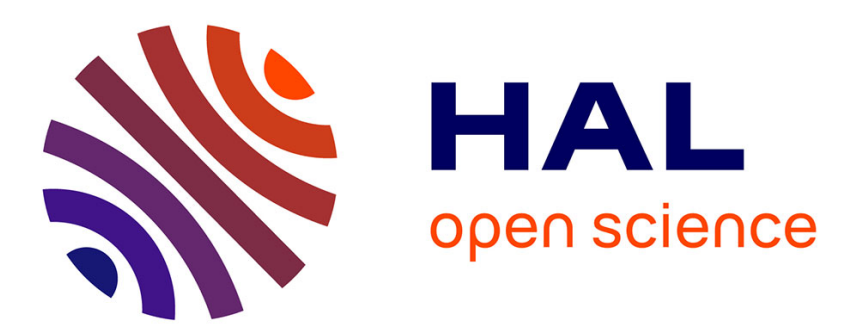

\title{
Big Data, Big Opportunities: Revenue Sources of Social Media Services Besides Advertising
}

Julian Bühler, Aaron W. Baur, Markus Bick, Jimin Shi

\section{To cite this version:}

Julian Bühler, Aaron W. Baur, Markus Bick, Jimin Shi. Big Data, Big Opportunities: Revenue Sources of Social Media Services Besides Advertising. 14th Conference on e-Business, e-Services and e-Society (I3E), Oct 2015, Delft, Netherlands. pp.183-199, 10.1007/978-3-319-25013-7_15 . hal01448038

\section{HAL Id: hal-01448038 \\ https://hal.inria.fr/hal-01448038}

Submitted on 27 Jan 2017

HAL is a multi-disciplinary open access archive for the deposit and dissemination of scientific research documents, whether they are published or not. The documents may come from teaching and research institutions in France or abroad, or from public or private research centers.
L'archive ouverte pluridisciplinaire HAL, est destinée au dépôt et à la diffusion de documents scientifiques de niveau recherche, publiés ou non, émanant des établissements d'enseignement et de recherche français ou étrangers, des laboratoires publics ou privés. 


\title{
Big Data, Big Opportunities: Revenue Sources of Social Media Services Besides Advertising
}

\author{
Julian Bühler, Aaron W. Baur, Markus Bick, and Jimin Shi \\ ESCP Europe Business School Berlin, Berlin, Germany \\ \{jbuehler, abaur, mbick\} @escpeurope.eu, \\ jimin.shi@edu. escpeurope.eu
}

\begin{abstract}
Facebook, Twitter, Instagram, and other players in the social media world have been on the rise during the last couple of years. In contrast to their popularity, their underlying business models are vague and often only linked to advertising. In this explorative study we identify new revenue sources for social media service providers besides advertising. Based on three use cases with $\mathrm{Fa}-$ cebook, Tencent, and LinkedIn, we identify three possibly fruitful ways to extend existing social media business models. Subsequently, a survey with 301 respondents changes perspectives on the user's willingness to pay in order to identify usage-related differences evoked by cultural and external circumstances. Four derived hypotheses lead the way to avenues of further research especially in terms of Big Data analytics with new e-commerce trends like Facebook's Buy Button.
\end{abstract}

Keywords: Social Media, Advertising, Business Models, Big Data, Case Study

\section{$1 \quad$ Introduction}

On January 30, 2015, one of the world's leading social media services Facebook [1] updated its terms and data policy significantly by introducing new advertisement rules [2]. Users had to accept these changes in order to be able to still use the service. The modifications helped Facebook be more efficient in online behavioral advertising by collecting user information from various websites automatically, with the help of cookies. This behavior suggests that advertising is still one of the most important revenue pillars in the social media world. For instance, Facebook reported that income from advertising represented 88\% of its total revenue in Q2/2013 [3] and increased to $93 \%$ in Q4/2014, compared to "payments and other fees revenue," comprising only $7 \%$ [4]. However, tracking user reactions to this personalized advertising automatically leads to a massive overload of information which require modern analytic processes like certain Big Data algorithms. Still it remains unclear how and if Facebook interprets the tracked data, as not necessarily storage or analysis, but effective and efficient transformation of Big Data into reliable information causes problems [5]. 
In contrast to this development, Clemons [6] already forecasted six years ago that advertising would fail to play a role as the leading revenue source for Internet-based companies. The author suggests that consumers tend to ignore advertising including online variations for three main reason: no trust in advertising, no willingness to see advertising, and no need for advertising at all to become informed [6]. The last argument is especially linked to the Internet as it has become easier for customers to collect all necessary information to decide on product purchases via search engines and product comparison websites. Therefore, it might be doubtful whether the focus on Big Data algorithms in advertising contexts is worth deeper research.

Since Clemons' analysis in 2009, the rise of social media has led to an unforeseen dominance of services including Facebook, Twitter, YouTube, and Instagram amongst others on the Internet. Thus, in this study we aim to identify existing alternative business models for revenue generation besides advertisement, as especially smaller or more specialized social media services struggle to capitalize on this single business model in the same way. The starting point for us to answer this question is a valuable categorization by Zambonini [7] that sheds light on other potential business models. However, social media was not considered explicitly despite the dominant position it has, nor did other promising studies recently (e.g., [8]). Until now, information systems (IS) or marketing research has not yet focused on operationalization of alternative revenue sources that trigger users' perceptions appropriately. In this empirical study we analyze different existing revenues, seeking to answer our main research question: Which revenue sources besides advertising should social media service providers utilize? Directly linked to this question are the underlying techniques in terms of suitable Big Data analytics routines [9].

The structure of this study is as follows. We first briefly discuss the term social media and its cognates as well as advertising in the context of this study (Section 2). Then we explain our research method, which contains three case studies of Facebook, Tencent, and LinkedIn and a survey with 301 participants (Section 3). Afterwards, we present three alternative revenue sources besides advertising based on the case study results and analyze them from the perspective of social media users (Section 4). We conclude this explorative study by deriving research hypotheses for accurate theory development in this field of study and with respect to Big Data analytics.

\section{Conceptual Background}

\subsection{Definition of Business Model and Social Media Services}

Before analyzing existing business models besides advertising in the social media environment, it is necessary to briefly clarify our understanding of these terms. We follow the definition introduced by Osterwalder and Pigneur [39, p. 14] who define a business model as 'the rationale of how an organization creates, delivers, and captures value". In addition and according to Kaplan and Haenlein [10, p. 61], 'social media services' can be understood as "a group of Internet-based applications that build on the ideological and technological foundations of Web 2.0, and that allow the creation and exchange of User Generated Content." The term 'social media services' is also 
linked to Web 2.0 by other authors and frequently used similarly to the expression 'social network' or 'social network site' (SNS) (e.g., [11-13]). We follow the first definition from Kaplan and Haenlein as it addresses the most relevant attributes of social media, but we consistently use the term social media services instead of social network (sites) in this paper. In the context of Big Data infrastructure, social media services are an appropriate object of study as they can serve as a certain 'source type'.

\subsection{Advertising as Financial Source for Social Media Services}

Of 16 business models analyzed by Zambonini [7], advertising is the most common financial source for all web-based services and applications and can be classified as third-party supported revenue, which also includes social media services. Facebook as one of the largest social media services "had third quarter advertising revenue of $\$ 1.8$ billion" [14, p. 1], being the largest share of overall revenues of $\$ 2.02$ billion. Traditional online advertising is randomly displayed on the screen of a user, unrelated to the person's demographic characteristics, cultural background, or user preferences. While this type of advertising was used by many providers in the first years of their existence, only a few - including one of the largest microblogging services from China, Sina Weibo - are still using this advertising strategy.

A more common variation nowadays is user-related advertising. It is a kind of targeted advertising that exploits user data to personalize the ads shown with the goal of increasing the click through rate and the conversion rate. It entails elements of users' data (e.g., language and location) [15], browser history (by means of cookies saved in browsers), and social media activities. All of these social media related activities are tracked, recorded, and registered into a social graph, which provides advertisers with relevant data. However, a problematic "industry-driven obsession with the 'social graph"” [16] can occur if the underlying Big Data analysis procedures are too technical and lead to invalid interpretations of activities. Such activities may comprise the action of adding contacts, Facebook Likes on a page or post, as well as comments on other users' timelines and actions that involve online applications such as games, music, or news. Facebook's latest terms of January 2015 stretched the area of influence significantly, allowing the company also to retrieve remote information from other websites or digital services. Mobile advertising which is not explicitly addressed in this study adds the component of accessibility and local optimization to this concept. This enables location-based service functionality and, thus, timed place-sensitive advertisements such as notifications of sales and special events [17].

\section{Research Method}

\subsection{Research Design: Case Study Analysis}

We chose a case study approach because it is suitable for our explorative setting. According to Yin et al., "A case study is an empirical inquiry that investigates a contemporary phenomenon in depth and within its real-life context, especially when the 
boundaries between phenomenon and context are not clearly evident" [18, p. 13]. Following the meta-analysis on case study research by Dubé and Paré [19] for methodological procedure, we postulated a clear research question in the introduction. Based on our general social media service definition, we decided to apply a multiple case design to accurately address both the diverse functionality of services and cultural diversity of users. All main elements, which are described in this and the next subchapter, are summarized in the complete visualization of our research model and approach (Table 1).

We used the Alexa website ranking [1] to identify the most globally used social media services and to distinguish between two types of social media services for our cases: entertainment-oriented social media services and business-oriented social media services. For us, entertainment-oriented social media services focus on general social networking tasks like picture sharing, pin boards, and gaming and emphasize predominantly leisure activities. On the other hand, we consider a business-oriented social media service as a service designed to share people's skills and professional interests, and to promote oneself. Together, these two variations form our unit of analysis [19].

Table 1. Research model and approach

\begin{tabular}{|c|c|c|c|}
\hline \multicolumn{4}{|l|}{ Research Design } \\
\hline $\begin{array}{l}\text { Clear Research Question } \\
{[20-23]}\end{array}$ & \multicolumn{2}{|c|}{$\begin{array}{l}\text { Multiple Case Design } \\
{[18,20,24]}\end{array}$} & Unit of Analysis [18] \\
\hline $\begin{array}{l}\text { "Which revenue sources } \\
\text { besides advertising should } \\
\text { social media service provid- } \\
\text { ers utilize?" }\end{array}$ & \multicolumn{2}{|l|}{$\begin{array}{l}\text { - Facebook } \\
\text { - Tencent } \\
\text { - LinkedIn }\end{array}$} & $\begin{array}{l}\text { Type A: entertainment- } \\
\text { oriented social media ser- } \\
\text { vices } \\
\text { - Type B: business-oriented } \\
\text { social media service }\end{array}$ \\
\hline \multicolumn{4}{|l|}{ Data Collection } \\
\hline \multicolumn{4}{|c|}{ Multiple Data Collection [18, 25] } \\
\hline \multicolumn{4}{|c|}{$\begin{array}{l}\text { - Website analysis of three social media services (incl. terms of use, sitemaps, FAQs, and user } \\
\text { accounts) } \\
\text { - Questionnaire addressing social media users and their willingness to pay for features, func- } \\
\text { tions, or services }\end{array}$} \\
\hline \multicolumn{4}{|c|}{ Data Analysis } \\
\hline \multicolumn{2}{|c|}{ Logical Chain of Evidence $[18,20]$} & \multicolumn{2}{|c|}{ Cross-Case Patterns $[21,23,26]$} \\
\hline \multicolumn{2}{|c|}{$\begin{array}{l}\text { - Identification of relevant social media ser- } \\
\text { vices (Step 1) } \\
\text { - Identification of existing revenue sources } \\
\text { (premium features, services, etc.) besides } \\
\text { advertising (Step 2) } \\
\text { - Analysis of users' willingness to pay for } \\
\text { these offers (Step 3) }\end{array}$} & \multicolumn{2}{|c|}{$\begin{array}{l}\text { - Similarities and differences of willing- } \\
\text { ness to pay for offers for both social me- } \\
\text { dia service types A and B } \\
\text { - Empirical analyses as the basis }\end{array}$} \\
\hline
\end{tabular}


Following the Alexa ranking, we focused on the two leading entertainment services and the largest business service. First in the ranking is Facebook, which is not only the leading entertainment-oriented social media service according to our categorization, but also the most viewed website overall, second only to Google. In addition, we selected Tencent as a second entertainment service because it is present in a large, but partly restricted, market - China - and can reveal unknown phenomena. This cultural and legal distinction is in line with Yin's definition of adequate case selection [18]. Tencent as a portal is also present with two services in the Top 20, Qq.com and Weibo.com. Regarding the business-oriented social media services, we chose LinkedIn, which is the unchallenged worldwide leader and reaches the 13th rank in the Alexa ranking of all websites (not only social media services) [1].

\subsection{Multiple Data Collection: Website Analysis and User Survey}

According to Dubé and Paré's [19, p. 615] analysis of Sawyer [25] and Yin [18], "A major strength of case study data collection is the opportunity to use many different sources of evidence to provide a richer picture of the events". Hence, a multiple data collection approach was used as we first analyzed the three selected social media service websites with regard to offered revenue sources besides advertising. In addition, we developed a questionnaire to identify users' perceptions and adoption of these business models especially with respect to cultural and legal differences.

The general data collection phase was thus split into two parts (A \& B) as well, starting with an exhaustive website analysis including terms of use and sitemaps (A). We additionally created user accounts on all three services to gain an overview of all offered functions and services that could potentially serve as alternative revenue sources for the service providers. After the selection of Facebook, Tencent, and LinkedIn (Step 1), this identification of revenue streams ties in afterwards as a second step within a logical chain of evidence. We then distributed a questionnaire to a nonspecific target group of social media users in a second part of the data collection phase (B) to identify their willingness to pay for additional services and functions (Step 3).

The questionnaire itself is separated into three main sections and follows a funnel approach design [27], starting with questions on the demographic and socioeconomic situation of the participants. In the second section, we address the general usage of social media services and ask participants about their level of activity on associated social media websites. For all social media services they use with an individual account, conditional questions are designed to gather information on their willingness to pay for certain extra features, which we identified during the website analysis. The third section focuses on identifying social media services in professional or business surroundings in particular. We aimed to gain insights on user behavior here because we especially expected services such as LinkedIn to earn money with alternative business models besides advertising. We ask participants to give reasons why they use these services and which types of premium functions, upgrades, or other functionalities are subject to costs. Both for entertainment- and business-oriented services, participants are also requested to state prices they expected to pay for these extra fea- 
tures. This allows us to identify cross-case patterns between the three case studies. The final part of our questionnaire addresses how users intend to use these services in the future.

As this is an explorative approach, we have the goal of making inferences on a broad and random sample of the population and do not define a concrete target group for this study. Thus, possible exclusions of participants due to potential group bias issues can be avoided a priori $[27,28]$. The only characteristic participants have to fulfill is that they are Internet users and/or have Internet access regularly. This single criterion is helpful to address participants who are already online and probably active on or familiar with social media services. In line with the population we strive for, i.e., Internet users in general, we designed our questionnaire to be digital, not paperbased. Even though a few users might not be able to access the survey without hindrance due to technical problems or lack of support [27,28], it is an appropriate distribution means in our context. Therefore, the link to the corresponding survey was spread through various channels. This includes several mailing lists, social media services, and instant messengers as well as offline notices with short links and QR codes to our survey at many physical locations like universities and stations, being accessed by heterogeneous visitors.

\section{$4 \quad$ Analysis and Results}

\subsection{Case Studies: Identification of Alternative Financing Strategies}

\section{Case Study 1: Virtual Goods on Tencent.}

In our first case study, we focused on one of the largest social media service providers worldwide, the Chinese company Tencent. It offers several services via its platform qq.com (Alexa rank 10) like China largest social networking site similar to Facebook called $Q$ Zone, a microblogging service similar to Twitter called Weibo, and other services like instant messaging (WeChat) or games ( $Q Q$ Game). We decided to analyze Tencent besides its high ranking as it represents a large target group of Asian social media users as well as a broad variety of services and functions.

We analyzed the website including subpages and logged in as regular users to receive insights from their perspective. Besides advertising, we initially learned that Tencent has created thousands of different virtual goods for their numerous services. These virtual goods are offered to users for money and can be seen as "intangible objects purchased in order to be used in online communities such as SNS sites or online games. They also comprise virtual money (or virtual currency) which is used to purchase these intangible or physical goods" [29]. Ho and Wu [30, p. 208] investigated user's intention to purchase virtual goods especially in online games and according to the authors they became "a major source of income" for service providers. As especially the "social dimension [...] is likely to influence the purchasing intentions of 
individuals" [31, p. 790], virtual goods can play an important role not only for online games but social media service providers in general.

From what we found, the virtual goods offered by Tencent can be divided into two categories by their functions. The site offers goods with customization purposes, such as wallpapers and decorations for personal space. Virtual goods of this category are mostly offered on the social networking service Q Zone, but can also be found on WeChat in terms of emoticon stickers for chatting or outfits and cosmetics for customizing one's avatar. The second category consists of virtual goods offered for gaming purposes, such as tools and credits which users can utilize in certain games. According to Guo and Barnes [32], this is both an emerging trend for South Korea and China as Asia's biggest gaming markets as well as the USA (currently the largest egaming market). Unlike other social media services, e.g., Facebook, Tencent does not open itself as a platform for third party developers to offer their own games but soleily develops its own game.

After analyzing the offered types of virtual goods, it is important to clarify how Tencent is actually earning money with them. The company uses its own virtual money called Q coin which users can buy to purchase the virtual goods. The value of Q coin is connected to the Chinese currency Renminbi (CNY) and $10 \mathrm{Q}$ Coins are worth $10 \mathrm{CNY}$ (or $\approx 1.6 \mathrm{USD}$ ). This virtual money can be bought via different channels, such as QQ's official online payment site, mobile credits, post offices, convenient shops, or even newspaper stands around China. Purchased this way, Q coin serves like a prepaid card that users need to purchase in advance to deposit the equivalent money into their account. A second option is offered by Tenpay, which is a third party payment platform launched by Tencent connected with users' debit / credit card account or other online payment solutions such as PayPal. Once bought, users can share the same account information to purchase virtual goods with Q Coins among all the social media services of Tencent.

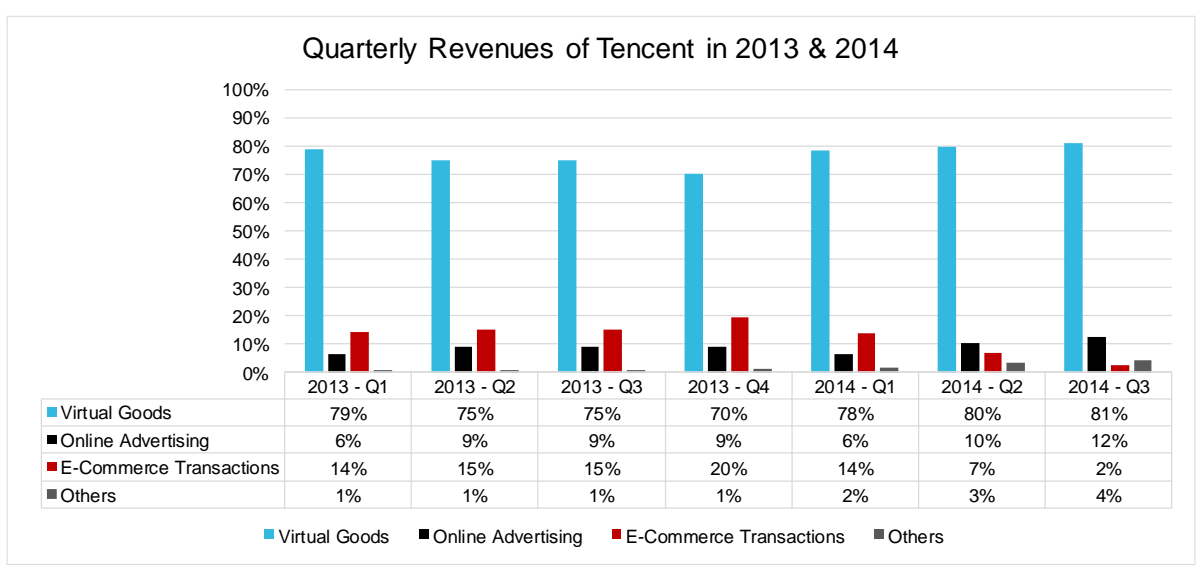

Fig. 1. Comparison of revenue sources for Tencent in 2013 \& 2014 (Source: [35]) 
From this case study analysis we summarize that Tencent follows a strategy which allows its users to have free registration in order to maximize users' acquisition. Afterwards Tencent starts to push its charged virtual goods to the users which upgrade their accounts or improve their social media experience. This paid upgrade of user accounts to a premium one, which entails the possibility to exploit several different features precluded to the free accounts, is the main characteristic of the popular business model denominated "freemium" [33]. The term "freemium" describes a business model which combines "'free' and 'premium' consumption in association with a product or service" $[34$, p. 1]. Fig. 1 shows that unlike most other social media service providers, the biggest proportion of Tencent's revenues is not advertising but virtual goods. Sold with the help of the freemium concept, they had a share between $70 \%$ (minimum, Q4/2013) and of 81\% (maximum, Q3/2014) over the total revenues in the last two years [35]. These results suggest that Tencent was successful in establishing a financing method for its social media service besides advertising.

\section{Case Study 2: e-Commerce and social commerce services on Facebook and} Tencent.

Social media services can also provide users with e-commerce functions within their environment, for example online trading and payment services. Functionalities including transactions between businesses and customers (B2C, as well as B2B and C2C) are often offered on the website of the social media service or as a third party payment platform on other websites. We analyze these activities which are sometimes referred to as social commerce in our second case study.

In the context of e-commerce functionality, Facebook seems to follow a strategy of trying out several approaches very fast according to our analyses. During the last couple of years, Facebook first had started with a service called Credits. Facebook Credits was a payment service for its platform of games and apps, developed and offered by third party developers. Users could purchase Facebook Credits and then convert them automatically into the in-game or in-app items they need. Facebook served as an online payment service and all purchases of virtual goods for applications and games on Facebook's platform were processed through Facebook Credits, the only payment option [36]. This service started in 2011 and developers earned 70\% of the value while Facebook retained 30\%. It was later replaced in 2013 by a service called Local Currency Payments, a service that converts the value of a virtual good into local currencies of users. The most common payment channels are credit card/debit cards, PayPal and mobile technologies (e.g., Google Wallet), but alternative local payment methods exist, varying from country to country [37]. For example, Moneybookers is available in the U.S. and Giropay in Germany. The service fee charged from game and app developers remained unchanged. The latest changes include Facebook Gifts, an online trading platform offered by Facebook in September 2012, where users could buy physical 3rd party company gifts or vouchers for their friends. This service was closed in 2014 and at the moment, users can only buy vouchers in the form of game cards in some countries. After various tests, Facebook 
will most likely introduce a new e-commerce feature called Buy Button in 2015, which allows third party companies to publish posts directly via the Facebook profile. The buying process for users is supposed to be easier as purchases can be made without leaving Facebook's website.

Besides the virtual goods business described in the first case study, our website analyses reveal that Tencent also play an important role in China's e-commerce sector. There are two individual services, PaiPai.com and Tenpay, which both are connected with Tencent's social media services like Q Zone. According to Tencent, PaiPai.com is a B2C \& C2C online trading platform launched in 2006 where users can find products from different categories, for example, clothing, electronic or education products [38]. They can log-in with their account from Tencent and every purchase can be shared among the various services. The business model of PaiPai.com is not based on account fees, which do not exist for sellers, but on added values. Sellers can buy trust certificates and receive in return e.g. extra space for larger product pictures in high resolution. The second e-commerce service offered by Tencent is Tenpay, which can not only be used to buy Q Coins, but also for regular bank transactions like online payments, money transfers, or others. Unlike Facebook's payment methods, Tenpay is a third party payment method available not only for Tencent's social media services, but also for the platforms of other companies.

Results of this case study with both companies reveal that major social media services are currently active in the e-commerce sector and even though Facebook changed its strategy over the years, e-commerce seems to be a promising alternative financing strategy to advertising.

\section{Case Study 3: Account upgrade services on LinkedIn.}

In our third case study, we analyze LinkedIn ${ }^{1}$ as the world's largest representative of other business-orientated social media services like Xing or Viadeo. LinkedIn offers a previously described freemium business model including four types of certain premium and account upgrade services. The first one is named job seeker and is designed for individual users looking for a new job opportunity. The second option is labeled as business plus, where experienced LinkedIn users can use extra functionality, such as additional search features. Sales plus is supposed to be used by salespeople looking for new leads or business partners and Recruiter Lite is dedicated to company representatives seeking for new employees via the LinkedIn platform. In addition to these four premium subscriptions, LinkedIn offers two additional premium services called Talent Solutions and Marketing Solutions. Talent Solutions is designed to support larger companies during their recruiting process while Marketing Solutions allows customers to present their content in a prominent position both on LinkedIn's website and the mobile app. Once users subscribe to one of the upgrade options, they get access to features included in the premium package.

\footnotetext{
${ }^{1}$ Service description of LinkedIn: https://www.linkedin.com/about-us
} 
We consolidated LinkedIn's information of the quarterly revenue reports ${ }^{2}$ and Fig. 2 illustrates the revenue sources for 2013 \& 2014. They indicate a successful adoption of the freemium concept with steadily growing revenue over the years. Anticipating similar results for 2015 following the recent trend, we consider this business model being a potential alternative financing strategy to advertising for social media service providers as well.

The business model advertising was previously categorized as third-party supported. In contrast, the analyzed business model account upgrade services comes within limits of subscription, pay for additional premium content or advanced features. Both virtual goods (here: virtual products) and e-commerce belong to payments according to [7]. All three alternative models identified in the case studies build the underlying structure for our second empirical part of this paper, a survey which includes participants in the core target markets of social media services, China, the USA, and Europe.

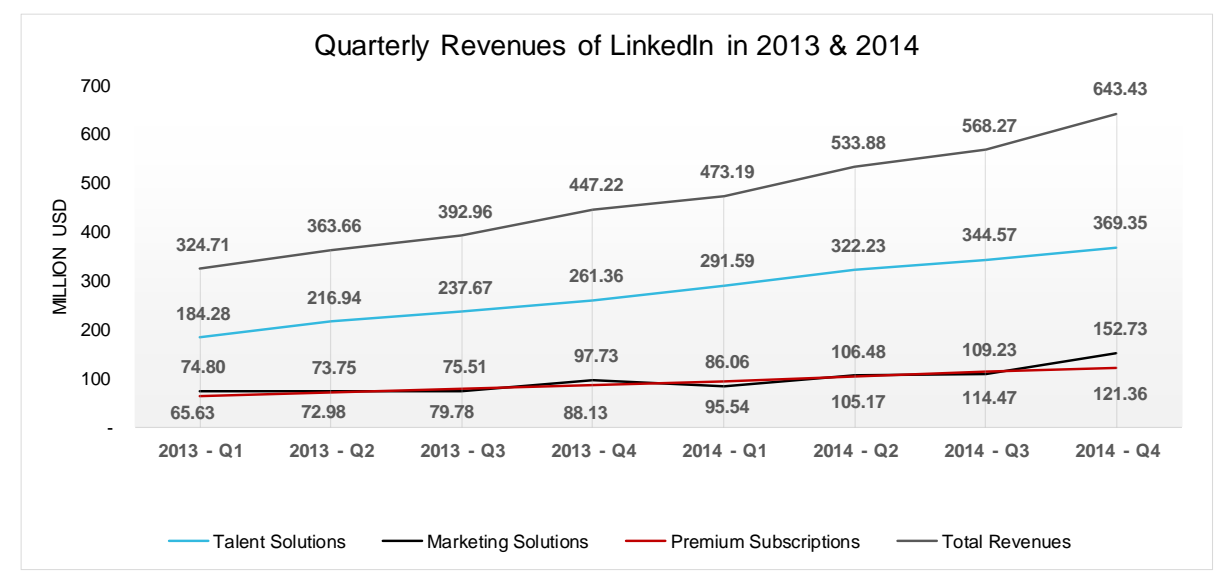

Fig. 2. Comparison of different revenue sources for LinkedIn in 2013 \& 2014

(Source: LinkedIn revenue reports, http://investors.linkedin.com/results.cfm)

\subsection{Survey Results}

Demographic Structure. After a period of six weeks we received 333 responses to our online survey in total. Out of these participants, 31 did not fully complete the survey and were excluded from our sample and further analyses. One additional participant was removed from our sample due to insufficient data reliability, which results in a final sample size of $\mathrm{n}=301$ respondents. The demographic distribution of our final sample is illustrated in Table 2, revealing non-representativeness but wide range regarding the age and varying nationalities of the participants, as strived for:

\footnotetext{
${ }^{2}$ LinkedIn: Quarterly Earnings 2013/2014: http://investors.linkedin.com/results.cfm? Quarter=\&Year=2013 and http://investors.linkedin.com/results.cfm?Quarter=\&Year=2014
} 
Table 2. Demographic distribution of survey respondents

\begin{tabular}{|c|c|}
\hline Demographic Category & Distribution \\
\hline Age & 33.7 years (sd: 11.1$)$ \\
\hline Gender & $61.1 \%$ female, $38.9 \%$ male \\
\hline Nationality & $\begin{array}{l}20.27 \% \text { from North America (incl. } 14.95 \% \text { from the US, } \\
4.64 \% \text { from Canada) } \\
31.23 \% \text { from Asia (incl. } 26.25 \% \text { from China) } \\
45.18 \% \text { from Europe (incl. } 13.62 \% \text { from Germany, } 6.98 \% \\
\text { from Italy, } 6.31 \% \text { from France) } \\
3.32 \% \text { from other continents }\end{array}$ \\
\hline
\end{tabular}

Another important characteristic of the sample of respondents is their status of employment. The majority of participants stated they are employed for wages $(44.19 \%)$, followed by $21.93 \%$ who are students and $12.62 \%$ who are interns. The remaining participants are self-employed $(8.31 \%)$, currently looking for a job $(5.32 \%)$, retired from work $(3.65 \%)$, or in other employment $(3.99 \%)$. This sample structure is relevant especially with respect to the sections of the questionnaire dealing with willingness to pay. More than half of the participants - at least employees for wages and selfemployed people - can be considered to earn money with their job and, therefore, have the purchasing power to pay for virtual goods or premium functionality.

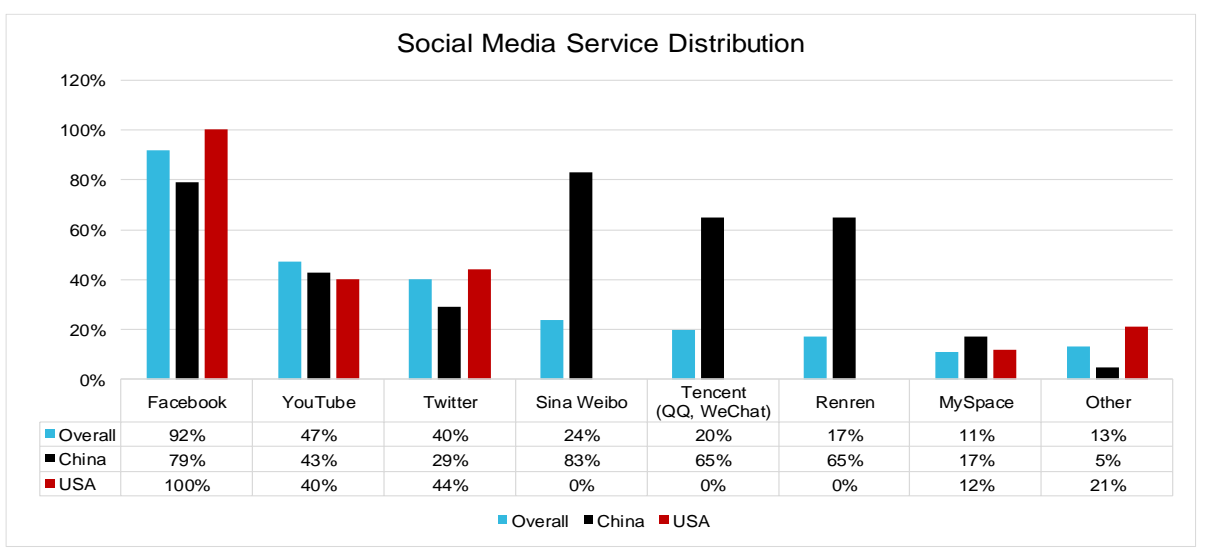

Fig. 3. Social media service distribution in China, the US, and worldwide (Source: own survey results)

Entertainment-oriented Social Media Usage. The popularity of social media usage among our survey participants is clearly visible according to the percentage of people with a subscription and account for at least one of the entertainment-oriented services. We provided predefined answers for seven important social media services, but respondents could name additional services in a text box. Results show that $92.69 \%$ $(\mathrm{n}=279)$ of the respondents have subscribed to a social media service and an additional $2.33 \%$ is planning to do so. Only less than five percent (4.98\%) of the sample is 
not interested in using social media services at all, right now, or in the future. Overall, results indicate a high level of activity as 265 of the 279 social media users in our questionnaire use the services at least once a week, $98.61 \%$ of them even once or several times a day. These results were measured on a 7-point Likert scale ranging from -3 ("I never use social media service") to +3 ("I use social media service a couple of times a day").

Going deeper into the analysis, the distribution of subscriptions to different social media services throughout our sample shows the clear supremacy of Facebook, followed by YouTube and Twitter. These results are in line with common rankings based on page impressions, e.g., the Alexa ranking, and confirm the dominant position occupied by this services globally. A more detailed look results from splitting the sample group into geographical clusters by continent membership. While Facebook reaches a saturation of more than $73 \%$ in all continents including Asia, even though access is technically restricted in China, other services vary significantly. As anticipated, all three Chinese-based social media services-Renren, Sina Weibo, and Tencent - are used by nearly $50 \%$ or more users in Asia but are virtually not recognized by those coming from North America or Europe. Fig. 3 gives an overview of the saturation of main social media services by continent.

Although entertainment-oriented social media services are being used quite heavily, our results indicate that purchases are relatively rare in this field. Only 31 respondents $(10.80 \%)$ bought additional functions or products. Age differences are not noticeable, but regarding the continent-based distribution, results clearly show that Chinese survey participants are the majority who purchased virtual products including virtual money on social media services. In our survey setting, participants were provided with certain offers like virtual goods we identified within the case studies, but they could also name other services or virtual goods. Respondents from Asia paid predominantly for premium accounts (e.g., Sina Weibo VIP accounts; Tencent QQ diamond account), virtual products (e.g., Tencent QQ avatar outfits, pets, and new themes; Tencent WeChat emoticon stickers), and virtual money (e.g., Tencent Q Coins). On the other hand, only survey participants from the US purchased Facebook gift cards, while Europeans had no particular key feature. On average, these 31 respondents spent $\$ 21.84$ for the additional functions and products (Fig. 4). These results clearly indicate a cultural difference in terms of usage interests between Asian (in particular Chinese) and European or North American social media users.

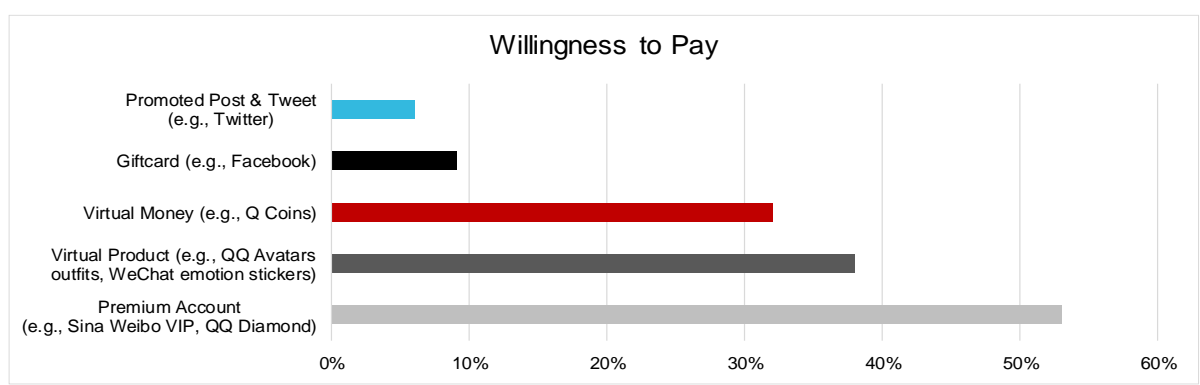

Fig. 4. Willingness to pay for selected functions and products (Source: own survey results) 
The last part of this second section of our questionnaire addressed the willingness to pay money for additional functions and products. Overall, social media services in this field have low potential here according to our results because only $3.97 \%$ of existing and prospective users stated their interest in spending money for these features on entertainment-oriented social media services. Of all offers, virtual products in the Asian market have the highest potential compared to others.

Business-oriented Social Media Usage. The final part of our questionnaire addressed business-oriented social media services. We provided the respondents with ten predefined answer options according to the ten most used services in Alexa ranking ( $\mathrm{Ab}$ solventa, Biznik, Cofoundr, Ecademy, E.Factor, LinkedIn, Ryze, Tianji, Xing, and Ziggs) and included an additional option to name "other service." The overall percentage of respondents using these services is significantly lower compared to entertainment-oriented services, but still $64.78 \%(\mathrm{n}=195)$ subscribe to one and $14.29 \%$ $(\mathrm{n}=43)$ plan to subscribe in the future. LinkedIn is the unchallenged leading service in this field with 168 users (55.81\%) within our total sample and 24 (7.97\%) of them from China. This is interesting as LinkedIn released its beta version of a simplified Chinese site only in February 2014 and a large new target group of Chinese-speaking members potentially joined the service since then. Other services than LinkedIn, in contrast to entertainment-oriented social media services, only play a role in individual regions and countries according to our results. For example, XING, a business network with similar functionality as LinkedIn, is used by 61 participants (20.27\%) even though it is only available in the German-speaking market and Spain. Viadeo was named by only three participants.

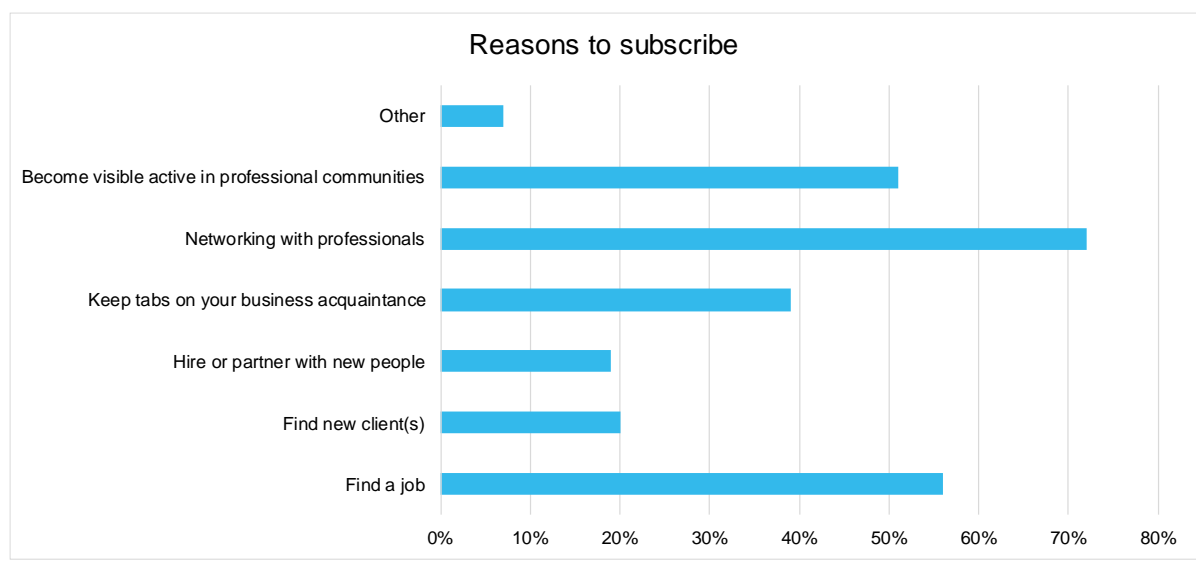

Fig. 5. Reasons to subscribe to business-oriented social media services

(Source: own survey results)

The next block of survey questions aimed at identifying reasons why users tend to use business-oriented social media services. Among the many possible reasons for subscription, three seem to be the most popular among our survey participants. Through- 
out all continents and countries, "networking with professionals" $(72.82 \%)$ is extremely important to our survey participants (Fig. 5). Business-oriented services in the social media world have given a completely new playground to the professional networking experience, so that many of our survey participants claim to use their accounts to find new professional contacts and share views, ideas, and know-how, alongside a new name in their contact lists. A second reason for 56.92\% in our sample is related to the recruiting purpose of such services, which is to "find a job." A detailed look at this option reveals that together with students (18.97\%) and interns (16.41\%), the survey participants who use a social media service like LinkedIn to find a job are mostly employed for wages (50.29\%). These results suggest that LinkedIn and others are nowadays an important tool used by employed people to steer their careers and to find new job opportunities. Additionally, visibility within professional communities ("Become visible active in professional communities," 51.28\%) as the third important option supports this line of argumentation.

These findings directly lead to the last part of this survey, which addresses the willingness to pay for premium functions in business-oriented social media services. Overall, $12.82 \%(\mathrm{n}=25)$ of the 195 users of these services stated that they already paid for premium features, and many of them confirmed in an open question design that gaining access to more features and functions in order to get in contact with new business partners was the main reason. Especially LinkedIn's direct mail function called InMail, which comes along with all payment models - analyzed in the third case study - seems to be a key function users are willing to pay for. Additionally, extended search functions including new algorithms (offered by, e.g., LinkedIn and XING) are important for both job seeking users and recruiters from companies. According to our results, the majority of the current users of such premium features $(88.00 \%)$ is satisfied with them and will keep the subscription.

Our survey participants could state in a text box the amount of money they are potentially willing to pay per month in total for business-oriented social media services. The answer range is quite broad, from a minimum of $\$ 1.81$ to a maximum of $\$ 113.00$. A distinct pattern with regard to willingness to pay does not exist according to these findings, since the results show a pretty high standard deviation $(\$ 21.04)$. But the average value of $\$ 17.00$ for all respondents, including potentially new members of these services, is comparable to the more frequently used entertainment-oriented social media services.

\section{Conclusion}

\subsection{Findings and Hypotheses}

With explorative case studies, we first identified three alternative business models, i.e., virtual goods, e-commerce, and account upgrade services. This extends the more general research by Zambonini [7] and Vukanovic [8]. We then analyzed the current user behavior on prominent entertainment- and business-oriented social media services. A clear focus was set in this second empirical part on questions directly related to willingness to pay for these extra functions or products. Results indicate that alter- 
natives exist to challenge the cash cow advertising. From our survey and our second case study we confirmed that virtual goods are particularly used for customization and gaming purposes, e.g., on Facebook or Tencent's Q Zone. On the other hand, account upgrades are bought by users of both types of social media services analyzed in this study, but predominantly on business-oriented ones like LinkedIn. Therefore we derive the following hypotheses, which can be tested in confirmative follow-up studies:

H1: Users of entertainment-oriented social media services tend to buy virtual goods while those of business-oriented social media services spend money on account-upgrade offers.

We could also identify differences in the use behavior influenced by what we think can be seen as three moderators: geographical location $(\mathrm{H} 2)$, age $(\mathrm{H} 2, \mathrm{H} 4)$, and availability of a service in a certain language (H3). These moderators change the relationship postulated in $\mathrm{H} 1$ :

H2: Asian users of entertainment-oriented social media services, especially younger ones, tend to buy more virtual goods and less account upgrades compared to Europeans and North Americans.

H3: Availability in a native language moderates the effect of users striving for business-oriented social media services for all users. The more languages offered by a business-oriented service provider, the more users will join the service.

H4: Age moderates the effect of striving for social media presence for all users. The older a user grows, the more he or she tends to be present in business-oriented social media services.

Business-oriented social media services are less present in Asia compared to Europe and North America, but this market penetration seems to have changed rapidly since the market leader LinkedIn made its services available in both the Japanese and Chinese languages. We think that this decision will boost memberships accompanied by a high potential of selling account upgrade services. With regard to our initially postulated research question, providers of entertainment-oriented social media services should concentrate on virtual goods in the gaming sector, especially with particular focus on Asian users. According to our results, they are open minded to alternative services and can set a trend, which could then be followed by European and North American users. In contrast, business-oriented service providers should utilize premium functions and account features as part of the well-established freemium concept.

\subsection{Limitations and Further Research}

In general, we could prove that users are willing to pay for additional features within social media services. However, this environment is absolutely fast moving with new ideas, functions, and implementations aspiring daily, like Facebook being on the brink of introducing its Buy Button after trying out several precursors. We had to set limits on this initial explorative approach, and we think that in addition to leading players like Facebook, Tencent, and LinkedIn, more and new emerging social media services like Instagram, which struggles to make money at the moment, should be examined as well. 
From the empirical data perspective, we gained a suitable sample size of 301 respondents for this explorative setting. The hypotheses deduced are based on data from individuals from all around the leading social media markets in North America, Asia, and Europe. This already covers a decent percentage of general cultural clusters. In upcoming studies, however, we suggest researchers narrow the scope of their empirical design to one of the core markets in order to shed light on specific cultural characteristics. We think further research with individual analyses, especially on users' willingness to spend money for extra services in these markets, could provide new insights.

The initial part of this research paper described Facebook's radical move of introducing new advertisement rules at the beginning of this year. Rather than being a gift for its users, this leading company in the social media environment consequently took the next step on the way to optimized user-related advertising. Right now advertising is by far the most profitable financing strategy of social media services. However, it is not the only effective one, as some players like Tencent demonstrate. Advertising is not the whole story when it comes to revenues, and new ways like virtual goods or freemium concepts are on the horizon. In the end, convenient e-commerce functionalities offered directly within a social media service-like Facebook's Buy Buttoncould be a condign revenue competitor to advertising. But regardless of the revenue source used, tracking the activities will be of utmost importance. Social media service providers should have this in mind, especially as "managing context in light of Big Data will be an ongoing challenge." [16, p. 671]

\section{References}

1. Alexa Internet Inc.: The Top 500 Sites on the Web, http://www.alexa.com/topsites

2. Facebook: Updating Our Terms and Policies: Helping You Understand How Facebook Works and How to Control Your Information, https://www.facebook.com/about/termsupdates

3. Melanson, D.: Facebook Reports \$1.81 Billion in Revenue for Q2 2013, 1.15 Billion Monthly Active Users, ttp://www.engadget.com/2013/07/24/facebook-q2-2013-earnings/

4. Statista: Facebook's global revenue as of 1st quarter 2015, by segment (in million U.S. dollars), http://www.statista.com/statistics/277963/facebooks-quarterly-global-revenue-bysegment/

5. Moorthy, J., Lahiri, R., Biswas, N., Sanyal, D., Ranjan, J., Nanath, K., Ghosh, P.: Big Data: Prospects and Challenges. The Journal for Decision Makers 40, 74-96 (2015)

6. Clemons, E.K.: Business Models for Monetizing Internet Applications and Web Sites: Experience, Theory, and Predictions. Journal of Management Information Systems 26, 1541 (2009)

7. Zambonini, D.: Monetizing Your Web App: Business Model Options, http://www.boxuk.com/blog/monetizing-your-web-app-business-models/

8. Vukanovic, Z.: New Media Business Models in Social and Web Media. Journal of Media Business Studies 8, 51-67 (2011)

9. Goes, P.B.: Big Data and IS Research. MIS Quarterly 38, iii-viii (2014) 
10. Kaplan, A.M., Haenlein, M.: Users of the world, unite! The challenges and opportunities of Social Media. Business Horizons 53, 59-68 (2010)

11. Chiang, I., Huang, C., Huang, C.: Characterizing Web users' degree of Web 2.0-ness. Journal of the American Society for Information Science and Technology 60, 1349-1357 (2009)

12. boyd, d., Ellison, N.B.: Social Network Sites: Definition, History, and Scholarship. Journal of Computer-Mediated Communication 13, 210-230 (2007)

13. Maier, C., Laumer, S., Weitzel, T.: Although I am stressed, I still use IT! Theorizing the decisive impact of strain and addiction of social network site users in post-acceptance theory. In: Proceedings of 34th International Conference on Information Systems. Milan, Italy (2013)

14. Wilhelm, A.: Facebook's Desktop Ad Revenues Fell \$26m in Q3 as Its Mobile Ad Revenue Surged \$226m, http://techcrunch.com/2013/10/30/facebooks-desktop-ad-revenuesfell-26m-in-q3-as-its-mobile-ad-revenue-surged-226m/

15. Gatto, K.: How Facebook Sells Your Personal Information, http://news.discovery.com/tech/gear-and-gadgets/how-facebook-sells-your-personalinformation-1301241.htm

16. boyd, d., Crawford, K.: Critical questions for big data. Information, Communication \& Society 15, 662-679 (2012)

17. Johnston, K.: What Are the Advantages of Mobile Advertising?, http://smallbusiness.chron.com/advantages-mobile-advertising-55314.html

18. Yin, R.K.: Case study research. Design and methods. Sage Publications, Thousand Oaks (1994)

19. Dubé, L., Paré, G.: Rigor in information systems positivist case research: current practices, trends, and recommendations. MIS Quarterly 27, 597-635 (2003)

20. Benbasat, I., Goldstein, D.K., Mead, M.: The Case Research Strategy in Studies of Information Systems. MIS Quarterly 11, 369-386 (1987)

21. Eisenhardt, K.M.: Building Theories from Case Study Research. Academy of Management Review 14, 532-550 (1989)

22. Mays, N., Pope, C.: Qualitative Research: Rigour and qualitative research. BMJ 311, 109$112(1995)$

23. Miles, M.B., Huberman, A.M.: Qualitative data analysis. An expanded sourcebook. Sage Publications, Thousand Oaks (1994)

24. Lee, A.S.: A Scientific Methodology for MIS Case Studies. MIS Quarterly 13, 33-50 (1989)

25. Sawyer, S.: Analysis by Long Walk: Some Approaches to the Synthesis of Multiple Sources of Evidence. In: Trauth, E.M. (ed.) Qualitative research in IS. Issues and trends. Idea Group Pub., Hershey, PA (2001)

26. Nisbett, R., Ross, L.: Human inference. Strategies and shortcomings of social judgment. N J Prentice-Hall XVI, Englewood Cliffs (1980)

27. Hair, J.F.: Multivariate data analysis. Prentice Hall, Upper Saddle River, NJ (2010)

28. Stopher, P.R.: Collecting, managing, and assessing data using sample surveys. Cambridge University Press, Cambridge, UK (2012) 
29. Javelin Strategy \& Research: Virtual Currency and Social Network Payments - the New Gold Rush: How Emerging Virtual Transactions Will Alter the Payments Landscape Forever, https://www.javelinstrategy.com/brochure/212 (2011)

30. Ho, C.-H., Wu, T.-Y.: Factors Affecting Intent to Purchase Virtual Goods in Online Games. International Journal of Electronic Business Management 10, 204-212 (2012)

31. Animesh, A., Alain, P., Sung-Byung, Y., Wonseok, O.: An odyssey into virtual worlds: exploring the impacts of technological and spatial environments on intention to purchase virtual products. MIS Quarterly 35, 789-810 (2011)

32. Guo, Y., Barnes, S.: Virtual item purchase behavior in virtual worlds: an exploratory investigation. Electronic Commerce Research 9, 77-96 (2009)

33. Anderson, C.: Free: the past and future of a radical price. Hyperion, New York (2009)

34. Niculescu, M.F. and Wu, D.J.: When Should Software Firms Commercialize New Products Via Freemium Business Models?, http://rady.ucsd.edu/faculty/seminars/papers/Niculescu.pdf (2011)

35. Tencent: Tencent Announces 2014 Third Quarter and Interim Results, http://www.tencent.com/en-us/at/pr/2014.shtml

36. Eldon, E.: Facebook Sets July, 1, 2011 Deadline to Make Credits Sole Canvas Game Payment Option, http://www.adweek.com/socialtimes/facebook-sets-july-1-2011-deadline-tomake-credits-sole-canvas-game-payment-option/255581?red=if

37. Facebook: Facebook Payments, https://developers.facebook.com/docs/payments/overview

38. Tencent: Tencent - Products \& Services - Ecommerce, http://www.tencent.com/enus/ps/ecommerce.shtml

39. Osterwalder, A., Pigneur, Y.: Business Model Generation: A Handbook for Visionaries, Game Changers, and Challengers. Wiley, New Jersey (2013) 